\title{
Fazendo a República: a agenda radical de Irineu Machado***
}

Américo Freire ${ }^{* * *}$

Irineu Machado foi um dos mais importantes políticos cariocas da Primeira República. Eleito deputado federal pela primeira vez em 1896, teve longa e atribulada carreira político-parlamentar até o advento da Revolução de 1930, quando veio a se afastar da cena política nacional. Para o acompanhamento e análise da trajetória deste ator político, sugere-se uma linha de interpretação que busca estabelecer diálogos e conexões entre as proposições defendidas pelo radicalismo republicano, de forte presença em vários países europeus e americanos, e a maneira pela qual Irineu Machado concebia e fazia política.

Palavras-chave: Republica - Radicalismo - Trajetória Política

Making the Republic: Irineu Machado's radical agenda

Irineu Machado was one of Rio de Janeiro's most important politicians during the first Brazilian Republic. Elected as a member of parliament for the first time in 1896, he went through a long and troubled political career until the 1930 Revolution,when he left the national political scene. In order to follow and analyze his political trajectory, this article proposes to expose arguments which seek to verify possible connections between republican radicalism and the way Irineu Machado conceived and made politics.

Keywords: First Brazilian Republic - Radicalism - Political Trajectory

\footnotetext{
*Artigo recebido em setembro de 2008 e aprovado para publicação em outubro de 2008.

** Este texto é uma versão modificada da comunicação que apresentei no Grupo de Trabalho sobre Primeira República no XII Encontro de História da ANPUH-Rio de Janeiro, realizado na Universidade Federal Fluminense em 2006.

*** Professor e pesquisador da FGV/CPDOC. E-mail: americo.freire@fgv.br.
} 


\section{La construction de la République: l'agenda radicale d'Irineu Marinho}

Irineu Machado a été un des plus importants politiciens cariocas (de la ville de Rio de Janeiro) dans la Première Republique. Elu deputé à l'Assemblée Nationale pour la première fois en 1896, il a eu une longue et mouvementée carrière politiqueparlementaire jusqu'à l'irruption de la Révolution de 1930, quand il s'est éloigné de la scène politique nationale. Pour suivre et étudier la trajectoire de cet acteur politique, on a choisi une ligne d'interprétation qui cherche d'établir des rapports entre les propositions soutenues par le radicalisme républicain, très important dans plusieurs pays européens et americains, et la manière par laquelle Irineu Machado concevait et faisait de la politique.

Mots clés: Republique - Radicalisme - Trajectoire Politique

A historiografia brasileira, ao estudar o radicalismo político na Primeira República, tem concentrado seus esforços na análise de três fenômenos, todos eles frutos das tensões que marcaram os primeiros anos do novo regime, a saber: o militarismo deodorista ou florianista, o ideário positivista e suas aplicações práticas, e o jacobinismo carioca. De uma maneira geral, a literatura, ao empregar o termo radicalismo para lidar com fenômenos tão diversos, o tem feito de forma bastante larga, qual seja, identificando-o a um conjunto de idéias ou práticas políticas - mais ou menos coerentes - que teriam como principal atributo o de interpelar - de forma intransigente - as estruturas de poder dominantes. ${ }^{1}$

Na passagem do século XIX para o XX, o termo radicalismo passou também a ser empregado para designar uma determinada corrente de opinião, por vezes organizada em agremiação partidária, que acabou por assumir um papel central na constituição e afirmação de regimes republicanos liberal-democráticos, tanto sem países europeus, como em americanos. Em diálogo com proposições conservadoras ou mesmo com leituras mais individualistas do liberalismo, este

\footnotetext{
${ }^{1}$ Antônio Candido, em ensaio sobre o pensamento radical brasileiro, também se vale de uma definição bastante abrangente sobre o radicalismo. Diz ele: "Pode-se chamar de radicalismo, no Brasil, o conjunto de idéias e atitudes formando contrapeso ao movimento conservador que sempre predominou. Este conjunto é devido a alguns autores isolados que não se integram em sistemas, pois aqui nunca floresceu em escala apreciável um corpo próprio de doutrina politicamente avançada, ao contrário do que se deu em países como o Uruguai, Peru, México e Cuba. Digo que o radicalismo forma contrapeso porque é um modo progressista de reagir ao estímulo dos problemas sociais prementes, em oposição ao modo conservador. Gerado na classe média e em setores esclarecidos das classes dominantes, ele não é um pensamento revolucionário, e, embora seja fermento transformador, não se identifica senão em parte com os interesses específicos das classes trabalhadoras, que são o segmento potencialmente revolucionário da sociedade." Conf. Antônio Candido, "Radicalismos". Estudos Avançados, 4 (8), São Paulo, 1990, p. 4-18.
} 
novo ator político, de fisionomia não muito precisa, apostou, em linhas gerais, na possibilidade da constituição de novos pactos políticos e sociais assentados na republicanização do Estado.

$\mathrm{Na}$ Europa, o caso que talvez melhor expresse esse novo fenômeno político seja o francês, haja vista a importância assumida pelos radicais na elaboração e configuração do "modelo republicano" naquele país, como também nos rumos políticos da Terceira República Francesa. ${ }^{2}$ Fundado em 1901, o Partido Radical francês manteve-se no poder até fins da década de 1930, com base em uma plataforma política cujo coração, nas palavras de Gerard Noiriel, era a defesa dos direitos do homem, da justiça e da laicidade. ${ }^{3}$

Na América, entre outras, registra-se, pelo seu significado e permanência, a experiência argentina caracterizada pela criação e atuação da União Cívica Radical (UCR), agremiação que jogou um papel decisivo na história daquele país, seja nas primeiras décadas do século XX, quando da instituição do voto universal, seja ao final deste mesmo século, quando o radicalismo formou com outros partidos para liderar o processo de transição da ditadura militar para um regime civil assentado em bases democráticas. ${ }^{4}$ De uma maneira geral, estas agremiações, no decorrer do século XX, ao serem acossadas pela expansão político-eleitoral de partidos de matiz marxista, terminaram por se deslocar gradualmente de um perfil original de centro-esquerda para posições centristas ou mesmo de centro-direita.

Quanto à Primeira República brasileira, ainda que o radicalismo não tenha se organizado como agremiação partidária, alguns de meus levantamentos preliminares me levam a crer que se deva avançar em linhas de investigação - nos moldes sugeridos pelos chamados "connected histories" ${ }_{5}$ - que busquem analisar

\footnotetext{
${ }^{2}$ Sobre a trajetória e o significado do radicalismo francês, cf. Serge Berstein e Odile Rudelle (sous da direction de), Le Modéle Republicain, Paris, PUF, 1992. Ver ainda Serge Berstein, Histoire du parti radical, vol. 1, La recherche de l'âge d'or, Paris, Presses de La FNSP, 1980 e Claude Nicolet, Le Radicalisme, Paris, PUF, 1957 (Que sais-je?, 761).

${ }^{3}$ Gérard Noiriel, Les origines républicaines de Vichy, Paris, Hachette Littératures, 1999, p. 68.

${ }^{4}$ Sobre as bases políticas da UCR, ver Natalio Botana e Ezequiel Gallo, De La Republica Posible a la Republica Verdadera: 1880-1910, Buenos Aires, Ariel Historia, 1997. Ver ainda Natalio Botana, El ordem conservador (1880-1916), Buenos Aires, Sudamericana, 1979.

${ }^{5}$ Para Roger Chartier, a linha dos "connected histories" se caracteriza pela produção de trabalhos que elegem objetos que se voltam para o exame de cadeias de interdependência que porventura se formam em contextos que ultrapassam as barreiras nacionais. Cf. Roger Chartier, La historia o la lectura del tiempo, Barcelona, Gedisa Editorial, 2007, p. 78-9. Ver tendências destes estudos em Sanjay Subrahmanyam, "Connected Histories: notes towars a configuration of Early Modern Eurasia", in: Beyond Binary Histories. Re-imagining Eurasia to c. 1830, v. Liberman (ed.), The University of Michigan Press, 1977, p. 289-315 e Serge Gruzinski, "Le mondes mêlés de la Monarchie catolique et autres 'connected histories", Annales. Historie, Sciences Sociais, 2001, p. 85-117.
} 
as possíveis formas de leitura - ou mesmo de apropriação - do programa e dos meios de ação dos radicais realizadas por determinados grupos republicanos brasileiros.

Para tal, tenho, em primeiro lugar, a título de hipótese, concentrado minhas lentes de análise no universo de políticos que giraram em torno de um dos mais importantes jornais brasileiros na Primeira República, o Correio da Manhã. Fundado por Edmundo Bittencourt, em 1901, portanto já em um momento de descenso do militarismo e do jacobinismo, o Correio - na medida em que pautou sua linha editorial por uma sistemática oposição aos grupos políticos dominantes, com base em um discurso centrado na defesa "da causa da justiça, da lavoura e do comércio, isto é, do direito do povo, do seu bem-estar e das suas liberdades" - ${ }^{6}$ ao longo da Primeira República, tornar-se-ia estuário para lideranças políticas e sociais que, por motivos variados, propugnavam por mudanças nas estruturas políticas do país. Dado o seu caráter de "jornal de opinião", o Correio da Manhã terminou por envolver-se diretamente nas contendas político-partidárias e eleitorais, ainda que se declarasse independente dos partidos.

Irineu Machado esteve entre os homens públicos que estabeleceram vinculações políticas mais estreitas com o Correio da Manhã. Eleito deputado federal pela cidade do Rio de Janeiro pela primeira vez em 1896, tornou-se, em pouco tempo, uma figura-chave na política carioca e brasileira até o advento da Revolução de 1930. No decorrer de sua carreira, formou, ao lado de jacobinos, florianistas, civilistas, socialistas e tenentistas, ou seja, manteve - direta ou indiretamente - conexões com alguns dos mais importantes movimentos que colocaram em xeque a ordem republicana. Para alguns de seus (muitos) adversários (ou inimigos), Irineu não era mais do que um demagogo a se valer de poderosa retórica. Já para parte da crônica política da época, era a própria encarnação do tribuno popular a açular as massas contra o regime.

Diante do exposto, me parece, portanto, que um estudo acerca da sua trajetória político-parlamentar possa nos ajudar a compreender melhor o que, à falta de melhor expressão, poderíamos chamar de "radicalismo à brasileira."

Este texto está dividido em três seções. Na primeira delas, são apresentados alguns traços gerais da trajetória profissional e política de Irineu Machado, ao mesmo em que se verifica a maneira pela qual a literatura tem lidado com

\footnotetext{
${ }^{6}$ Apud verbete "Correio da Manhã" de Carlos Eduardo Leal, in: Alzira Alves Abreu et alii (coord.), Dicionário Histórico e Biográfico Brasileiro pós-1930, Rio de Janeiro, FGV/CPDOC (CD-Rom).
} 
o personagem em tela. A seguir, são examinadas algumas das proposições políticas de Irineu Machado, tomando por base seus pronunciamentos junto à imprensa carioca. Em nota final, abre-se o foco de análise com o objetivo de melhor situar o personagem no universo do radicalismo republicano.

\section{Florianista, civilista e socialista}

Dunshee de Abranches, em Governos e Congressos da República dos Estados Unidos do Brasil, apresenta alguns dados sobre a vida e a formação de Irineu. Segundo ele, Irineu nasceu no Rio de Janeiro, em dezembro de 1872, formando-se Bacharel em Direito pela Faculdade de Direito de Recife, em 1892, e Doutor em Ciências Jurídicas e Sociais pela Faculdade Livre de Direito do Rio de Janeiro, em 1894. ${ }^{7}$ Nesse mesmo ano, já no Rio de Janeiro, começou a vida profissional como funcionário público na Estrada de Ferro Central do Brasil e no Ministério da Marinha, além de dar aulas na Faculdade de Direito do Rio de Janeiro. Em todos estes lugares, nos relata Michael Conniff, obteve um grande número de seguidores, seja entre os operários do Estado, seja junto aos estudantes. ${ }^{8}$

Naqueles anos, ao que tudo indica, Irineu já circulava com desenvoltura nos círculos políticos e intelectuais do republicanismo florianista, haja vista, por exemplo, o destaque com que se apresentou em uma importante homenagem oficial prestada a Floriano, em outubro de 1895, meses depois do falecimento do ex-presidente. Na ocasião, segundo o relato de Suely Robles de Queiroz, proferiu um violento discurso contra o governo do presidente Prudente de Morais, estando o próprio presente no evento. A atitude o fez perder um dos seus empregos públicos. ${ }^{9}$

\footnotetext{
${ }^{7}$ Dunshee de Abranches, Governos e Congressos dos Estados Unidos do Brasil, São Paulo, 1918, p. 653. Afonso Arinos de Melo Franco apresenta dados diferentes sobre a formação superior de Irineu Machado. Segundo ele, Irineu fora colega de turma de seu pai - Afrânio de Melo Franco - na tradicional Faculdade de Direito de São Paulo, em meados dos anos de 1880, tendo sido contemporâneo de alguns dos futuros próceres do novo regime, como Venceslau Brás, Delfim Moreira e Washington Luis. Cf. Afonso Arinos de Melo Franco, Um estadista da República: Afrânio de Melo Franco e seu tempo, Rio de Janeiro, José Olympio, v.2. p. 147.

${ }^{8}$ Michael Conniff, Política urbana no Brasil: a ascensão do populismo, Rio de Janeiro, Relume Dumará, 2006, p. 95.

${ }^{9}$ Suely Robles Reis de Queiroz, Os radicais da República: jacobinismo: ideologia e ação (18931897), São Paulo, Brasiliense, p. 35.
} 
Em 1896, lançou-se candidato avulso ${ }^{10}$ para a Câmara dos Deputados pelo $2^{\circ}$ distrito da capital, obtendo a eleição em uma conjuntura marcada pelo acirramento dos conflitos entre a facção conduzida por Francisco Glicério, do Partido Republicano Federal, e Prudente de Morais. Na Câmara, já como deputado, engrossou as fileiras dos grupos gliceristas que faziam dura oposição a Prudente de Morais, sendo depois acusado, em companhia do vice-presidente e de vários parlamentares, de ter se envolvido na conspiração que teve como desfecho o atentado a Prudente, em novembro de 1897.

Aberta a "temporada de caça" ao jacobinismo, Irineu submergiu. Em 1899, já durante o governo Campos Sales, optou por formar com grupos políticos cariocas de corte mais moderado, aproximando-se do situacionismo e das benesses governamentais, posição essa que se prolongou, em parte, durante o governo Rodrigues Alves, quando comandou facções políticas de apoio ao prefeito Pereira Passos.

Já durante a década em que a República brasileira esteve sob forte influência da liderança de Pinheiro Machado, ou seja, entre 1906 e 1915, Irineu, uma vez mais, deixa o situacionismo para se aproximar de Rui Barbosa, tornando-se, em pouco tempo, a principal voz do "civilismo carioca". Foi nessa conjuntura que, no embate com os governos de Nilo Peçanha e Hermes da Fonseca, sua atividade parlamentar ganhou maior expressão. Em certa ocasião, nos relata José Vieira, Irineu, ao denunciar o comprometimento de Nilo Peçanha com a candidatura oficial, vociferou, da tribuna da Câmara, para a sua platéia de estudantes: "ou neutralidade ou revolução". ${ }^{11}$

Naquele mesmo momento, dava-se também o início de uma longa e frutífera aliança entre Irineu e o Correio da Manhã, aqui já mencionada.

Nos anos 20, Irineu já havia se tornado um "figurão" da política carioca. Anos antes, rompera com Rui Barbosa e chegara ao Senado com apoio dos grupos políticos dominantes cariocas, capitaneados por Paulo de Frontin, com quem viveria às turras por toda a última década da Primeira República. Em

\footnotetext{
${ }^{10}$ A legislação eleitoral republicana, com vistas a assegurar o direito de representação das minorias, permitia o lançamento de candidatos avulsos. Para burlar este mecanismo e manter o controle da representação, a direção do Partido Republicano de cada estado, além de apresentar uma lista oficial de nomes, comprometia-se também com candidatos individuais fiéis à agremiação. No caso da cidade do Rio de Janeiro, dada a maior competição política, foi possível, por vezes, a eleição de políticos com um perfil como o de Irineu Machado, cuja principal característica era a de manter um certo distanciamento dos grupos políticos dominantes.

${ }^{11}$ Cf. José Vieira, A Cadeia Velha, Brasília/Rio de Janeiro; Senado Federal/Casa de Rui Barbosa, 1980, p. 192.
} 
1921, entrou de cabeça na campanha da Reação Republicana de Nilo Peçanha, tendo sido acusado de envolvimento no rumoroso caso das "cartas falsas", no qual o Correio da Manhã divulgou com estrépito cartas de Artur Bernardes com acusações acerca do comportamento do marechal Hermes e dos militares em geral. Como se sabe, a estratégia não surtiu efeito e Bernardes chegou ao poder.

Em 1924, Irineu levou o troco - terminou "degolado" na eleição para o Senado Federal. Depois de passar três anos na Europa, voltou ao país e foi eleito de forma categórica para o Senado, alcançando mais do que o dobro de votos do que seu oponente. Em 1930, ao contrário de grande parte da oposição parlamentar, apoiou Júlio Prestes contra Getúlio Vargas. Segundo Conniff, corria à boca pequena que o mesmo havia recebido 150 mil dólares ou estava à mercê de alguma chantagem para apoiar o candidato oficial. ${ }^{12}$ Porém, nada disso ficou mais tarde comprovado. Com a vitória da Revolução de 1930, abandonou a vida político-partidária.

\section{De herói civilista a líder populista}

Em minhas pesquisas, não tomei contato com nenhum livro publicado sobre este controvertido personagem. Nas fontes até agora consultadas, obtive poucas e esparsas informações sobre sua atuação como parlamentar e como chefe político, a maior parte delas extraída de obras de cronistas políticos como Dunshee de Abranches, José Vieira e Sertório de Castro.

Dois são os livros de Abranches que fazem menção a Irineu. Em Como se faziam presidentes - um relato nos moldes do que hoje poderíamos chamar de História imediata dos primeiros governos civis republicanos,$-{ }^{13} \mathrm{o}$ autor registra a atuação de Irineu em única e delicada situação, qual seja, quando da traição do parlamentar carioca aos seus ex-companheiros florianistas durante a gestão de Campo Sales na presidência da República. Abranches, que estivera ao lado de Irineu na oposição ao governo de Prudente de Morais, não o perdoou, chamando-o de "precioso cabalista" de votos para o oficialismo. ${ }^{14}$

Já em obra posterior, a aqui já citada Governos e Congressos..., Abranches se mostra mais discreto na apresentação da trajetória política de nosso per-

\footnotetext{
${ }^{12}$ Michael Conniff, op. cit., 2006, p. 96.

${ }^{13}$ A obra foi publicada em fascículos de jornal no ano de 1903. Para este trabalho, utilizei a edição publicada pela Livraria José Olympio, em 1973.

${ }^{14}$ D. de Abranches, op. cit., 1973, p. 290.
} 
sonagem. Após registrar as sucessivas eleições de Irineu para a Câmara dos Deputados, chama a atenção para a participação "proeminente" do parlamentar "na reação intitulada civilista contra a candidatura do Marechal Hermes da Fonseca à presidência da República". ${ }^{15}$ Abranches aborda ainda o fato de Irineu ter sido eleito deputado federal, por duas ocasiões, para representar tanto Minas Gerais como o Distrito Federal, fenômeno esse que diz respeito à maneira pela qual alguns parlamentares com perfil semelhante ao de Irineu conduziram suas carreiras durante toda a Primeira República.

Abranches conclui o perfil do parlamentar carioca registrando alguns aspectos da liderança de Irineu. Vejamos.

Jurista emérito e tribuno valoroso e eloqüente, versado em questões internacionais, tem produzido, dentro e fora do Parlamento, importantes discursos e escritos, gozando entre as massas populares de grande prestígio eleitoral. Presentemente, fixando residência em Paris, tem sido um dos mais ardentes propagandistas pela entrada do Brasil na grande guerra européia ao lado das potências da Entente. ${ }^{16}$

José Vieira, por seu turno, faz de Irineu um dos personagens-chave em seu livro de crônicas publicado em 1909 sob o título Cadeia Velha: memórias da Câmara dos Deputados. ${ }^{17}$ Por meio de um estilo divertido e irônico, o autor cria a figura de um político polêmico, arrebatador de platéias, um tribuno incorrigível capaz de desconcertar os seus adversários fiéis ao governo Hermes da Fonseca. Para Vieira, "Irineu era talentoso, combativo e muito popular. Já se tem revelado com tendências para o socialismo. As condições políticas impedem-no de combater por idéias que, decerto, professa". ${ }^{18}$

Já Sertório de Castro apresenta uma dimensão menos pitoresca de Irineu. Em seu A República que a revolução destruiu, publicado em 1932, o autor, em tom incisivo, coloca o tribuno carioca ao lado de Rui Barbosa no Panteão da campanha civilista, vista pelo autor como "radiosa", "esplendorosa". $\mathrm{Na}$ Câmara, afirma Castro, os líderes civilistas iluminavam aquele recinto tradicional com a eloqüência de oradores como Pedro Moacyr, Irineu Machado, Barbosa Lima e outros.

\footnotetext{
${ }^{15}$ D. de Abranches, op. cit., 1918, p. 654.

${ }^{16}$ Idem, ibidem.

${ }^{17}$ Para este trabalho, utilizei obra publicada em 1980 pelo Senado Federal em conjunto com a Casa de Rui Barbosa.

${ }^{18}$ José Vieira, op. cit., p. 48.
} 
Sertório menciona ainda a "degola" sofrida por Irineu nas eleições senatoriais em 1924. Segundo ele,

do Senado havia sido iluminado o mais temível de quantos adversários contavam o governo e a sua política - o sr. Irineu Machado. Vitorioso num pleito em que o terreno era disputado palmo a palmo; portador de um diploma que deveria ser considerado a expressão insofismável da verdade eleitoral, (...) [Bernardes] deu esse golpe brutal e desnecessário entregando uma cadeira de senador a um amigo ocasional, mas aumentou de forma considerável o poder ofensivo do inimigo que pretendia aniquilar. Mostrá-lo-ia um futuro não muito remoto. ${ }^{19}$

Afonso Arinos de Melo Franco, em sua vasta biografia sobre o pai, também registra a importância de Irineu na luta dos civilistas contra os desmandos da vida política na Primeira República. Para ele, Irineu, Alcindo Guanabara e Barbosa Lima eram a "trinca de ases" da Cadeia Velha, em 1909, destacando-se pela sua combatividade e cultura. ${ }^{20}$ Melo Franco, no entanto, em duas passagens do seu livro, não deixa de chamar atenção para determinados episódios na vida e na carreira política de Irineu, os quais colocam em xeque a imagem de tribuno civilista construída por autores como José Vieira e Sertório de Castro. Dessa forma, Melo Franco o retira, sem pejo, da galeria de heróis que compõem a sua apologia liberal. Vejamos essas duas passagens.

A primeira refere-se a um pronunciamento no qual Irineu menciona o drama pessoal de ter sido traído pela mulher, fato esse que resultou em um crime passional. Segundo Melo Franco,

Irineu desvenda perante a Câmara silenciosa o drama da sua vida íntima, a desventura conjugal, a humilhação da honra ferida, a dor que leva ao crime. Usa, para exprimir suas dolorosas recordações, das expressões mais cruas, por vezes mais grosseiras, como quando disse que não era dos que ficam a "roer os cornos em silêncio". (...) Seu discurso é uma página tremenda: é a explosão do desespero num nevropata disposto a tudo. ${ }^{21}$

Em outro trecho, Melo Franco dá detalhes a respeito da participação de Irineu no episódio das "cartas falsas", quando o mesmo manteve contatos com os falsários e viu nas cartas algo "muito bom para destruir a candidatura

\footnotetext{
${ }^{19}$ Sertório de Castro, A República que a Revolução destruiu, Brasília, Editora da UnB, 1982, p. 311 .

${ }^{20}$ Afonso Arinos de Melo Franco, op. cit., p. 623.

${ }^{21}$ Idem, ibidem, p. 644.
} 
Artur Bernardes”. Ao examinar o pronunciamento que Irineu fez na Câmara, acerca deste caso, Arinos faz comentários como o seguinte:

A resposta de Irineu [às acusações] foi de uma fraqueza surpreendente naquele duro lutador se não estivesse ele certo da sua falsa posição. A acusação de explorador, em si mesma, praticamente não responde. Prefere orientar o seu longo discurso em atacar Bernardes e a política mineira, contra a qual tinha velhos recalques. (...) Daí por diante, numa demagogia bem carioca (grifo meu), o discurso de Irineu se cinge a criticar um parecer de Bernardes (...) contra os excessos e a ineficiência do funcionalismo público federal. ${ }^{22}$

Em meados dos anos 70 e começo da década seguinte, em meio a um ciclo de renovação das ciências sociais e da historiografia política quanto ao tema dos "movimentos sociais urbanos", dois livros fazem menção direta à participação de Irineu em episódios críticos da Primeira República. Um deles, já aqui citado, é Radicais da República, de Suely Robles de Queiroz. Nele, a autora menciona Irineu como membro destacado do jacobinismo carioca, colocando-o ao lado de militares florianistas, positivistas, arrivistas, golpistas e etc. Uma vez que o objetivo da autora foi o de chamar atenção para aspectos gerais do radicalismo jacobino, pouco se pode extrair das formulações próprias de Irineu acerca do jacobinismo.

Já Michael Conniff, em seu estudo sobre a política urbana no Brasil, nas décadas de 1920 e 1930, desloca a figura de Irineu das posições de herói civilista ou de "demagogo amoral" para um outro lugar, bem mais confortável: o de precursor do fenômeno populista brasileiro. Para Conniff, Irineu, a despeito das acusações que pairavam a respeito da sua retidão da conduta - teria "ajudado a revolucionar a política do Rio, afastando-se da estreita representação clientelista e dirigindo-se para uma ampla coalizão de forças, usando qualidades carismáticas e pregando (não sinceramente, como se revelou) a reforma social". ${ }^{23}$

Portanto, como se percebe, temos muito pouco material analítico sobre Irineu, para além de informações esparsas e leituras rápidas sobre o seu papel na vida política carioca e fluminense. Mesmo em Conniff, o autor que mais se deteve em examinar a sua trajetória, o que temos é pouco mais do que um arquétipo do líder contestador com muito carisma e pouca convicção. De alguma forma expressando as análises típicas da década de 70, Conniff viu em

${ }^{22}$ Idem, p. 1026.

${ }^{23}$ Michael Conniff, op. cit., p. 96. 
Irineu um reformador avant la letre, a ultrapassar a estreiteza do clientelismo em direção à política de massas.

\section{Revisionista e "terrível oposicionista"}

Passemos agora a examinar algumas das proposições políticas de Irineu. Dentre as muitas entrevistas concedidas ao Correio da Manhã, durante a sua longa carreira, fiquemos tão-somente com três delas: a primeira, do ano de 1909, quando Irineu se lança como candidato avulso; a segunda, de 1912, já como líder civilista; e a outra, de 1927, quando retornou ao país para concorrer - e vencer - a eleição para uma cadeira no Senado pelo Rio de Janeiro.

Na primeira delas, Irineu alega o seu temperamento insubmisso a partidos e agremiações para apresentar-se como candidato avulso. A respeito da sua diretriz política, afirma-se como um hóspede dos republicanos. Diz ele:

Em 1897 ou 1898, combatendo, na Câmara dos Deputados, a supressão de diversas oficinas do Arsenal de Guerra desta capital e a dos arsenais de Pernambuco e da Bahia, fiz declarações que envolviam a afirmação de princípios socialistas e, de então para cá, minhas convicções vão dia a dia se acentuando. Por isso, na circular com que me apresentei candidato, há três anos passados, disse que era apenas um hóspede entre os republicanos, pois que, mais adiantado que eles, eu aguardava a organização de um partido socialista para ele filiar-me quando isto se desse. Permanece até agora a mesma situação e, por isso, continuo a ser entre os republicanos um hóspede que resiste com eles aos reacionários, mas cogitando sempre de ideais mais adiantados que os deles. ${ }^{24}$

Em outras ocasiões, como veremos adiante, Irineu continuou a fazer profissão de fé socialista sem deixar muito claro o que isso representava. Nesta mesma entrevista, defendia a revisão da vida política brasileira para

salvar o país dessa terrível adulação de todos os poderes, absorvidos inteiramente pelo executivo, e libertá-lo dos tiranos locais, tão importantes chamados oligarquias. O fetichismo pelo regime presidencial só existe na região dos que governam ou estão de cima. Imagina-se o que diria um presidencialista se vivesse em certos estados da República, onde os governadores nomeiam, demitem removem e só promovem aqueles que estão filiados ao seu grêmio político. Se um adversário do governo local é assassinado, se a propriedade é incendiada, tudo fica na ordem dos poderes locais. Não há meio de impedir que a polícia faça um inquérito a seu modo e que os tribunais locais, corruptos ou coagidos

${ }^{24}$ Correio da Manhã, 27 de janeiro de 1909. 
decidam à mercê da vontade, de vida, opinião pública, sem partidos. E quando se fala em intervenção, imediatamente bradam que isso é a anulação do regime federativo. A responsabilidade dos poderes locais não se dá e a evidência da nossa história política é que a federação não passa de uma ficção, enquanto que a tirania é o fato. Já lhe disse que sou socialista, mas por isso mesmo não oculto minha defesa da revisão. Sou francamente revisionista. ${ }^{25}$

Logo em seguida, desfere críticas tanto ao programa de proteção ao café - o qual é visto como privilégio concedido aos cafeicultores - como à política de fixação de taxas ao açúcar estrangeiro. Para Irineu, no final, era o consumidor que "paga o pato". Segundo ele,

não há entre nós protecionismo: há, sim, proteção a determinados fabricantes. Não há entre nós nenhum plano para desenvolvimento das forças econômicas do país e as tarifas da Alfândega são um embaraço tremendo para o desenvolvimento do consumo e a educação artística do consumidor. ${ }^{26}$

Finalmente, volta-se para a defesa de seu eleitorado preferencial: o funcionalismo e o operariado. Propõe melhores condições para a Estrada de Ferro Central do Brasil, da qual foi funcionário e tem muitos amigos, a formação de um montepio do funcionalismo público e a criação do direito operário, o qual, segundo ele, não existe entre nós. Defende cooperativas, a regulação do trabalho das crianças e mulheres, além de indenizações por acidente de trabalho.

Em 1912, o Correio da Manhã relata as mil atribuições de Irineu na campanha. Segundo o jornal, em poucas horas,

o terrível oposicionista fala com metade do eleitorado carioca, passa bilhetes, entrega chapas, passa telegramas, acompanha Rui Barbosa em reuniões... Fatigado, o político discorre sobre as suas atribulações e como deseja se retirar um pouco de cena, mas só o fará quando o país tiver condições de livrar-se das algemas do hermismo e do pinheirismo e poder seguir o seu destino.

Para Irineu, "o país vive uma fase infame e que, nesse momento, não poderia fugir à luta. Seria uma vergonha, uma desonra". ${ }^{27}$

Sobre os seus projetos a serem apresentados na Câmara, Irineu, uma vez mais, faz menção ao apoio do funcionalismo e do operariado. Diz ele:

\footnotetext{
${ }^{25}$ Idem.

${ }^{26}$ Idem.

${ }^{27}$ Correio da Manhã, 24 de janeiro de 1912.
} 
"Estou na Câmara de 15 para 16 anos, sempre dedicado aos operários e aos funcionários públicos, serei o mesmo advogado de sempre, o mesmo amigo fiel de todos os tempos". ${ }^{28}$

Ao concluir a entrevista, afirma: "Entre nós tudo está por fazer. Já se disse que era preciso descobrir o Brasil. Não é tanto assim. A paráfrase, entretanto, é de absoluta verdade: devemos dar-lhe independência e civilizá-lo". ${ }^{29}$

Em 1927, Irineu, em nova entrevista ao Correio da Manhã, apresenta-se como líder das hostes revolucionárias. Segundo ele, o país vivia uma situação revolucionária. Diz:

A Revolução não está nas hostes de Prestes, mas no poder, na ação dinamiteira às garantias liberais. A Revolução está no poder, toda vez que atenta contra as leis. Revolução não era o que faziam os legionários de Prestes, que lutavam pela dignidade, pelas tradições liberais. ${ }^{30}$

Em seu depoimento, Irineu homenageia os heróis do "18 do forte" e a luta revolucionária contra a tirania de Bernardes. Faz ainda defesa apaixonada do Código do Trabalho, parado no Senado. Na ocasião, assume as teses do Bloco Operário Camponês, recordando o seu passado de fundador do Partido Socialista, em 1912. Finalmente diz que, se eleito, irá defender a anistia aos rebeldes e manter a sua luta em prol do funcionalismo.

\section{Radicalismo e republicanismo}

Ao concluir este breve perfil de Irineu Machado, creio que se faça necessário, preliminarmente, explorar um pouco mais a hipótese acima levantada quanto às possíveis conexões entre Irineu Machado e o radicalismo político republicano.

Dois podem ser os níveis de análise para lidarmos com essas conexões. Em um nível, cabe uma breve menção a determinados temas de natureza programática. Em seguida, passemos a observar aspectos mais diretamente relacionados com o padrão de atuação política dos atores em tela. Vejamos.

Em relação ao programa radical, anteriormente mencionado em suas linhas gerais, me parece que é mister chamar a atenção aqui tão-somente para a luta empreendida por esta corrente política em torno da defesa do reconhe-

\footnotetext{
${ }^{28}$ Idem.

${ }^{29}$ Idem.

${ }^{30}$ Correio da Manhã, 20 de fevereiro de 1927.
} 
cimento e da ampliação de direitos para o cidadão, seja no que concerne aos direitos humanos, seja quanto à ampliação da franquia do voto, seja, finalmente, na defesa de direitos sociais, com destaque para a reivindicação em torno do avanço da escolarização.

Ao se comparar o receituário de Irineu com o programa radical, é possível sugerir algumas aproximações, particularmente no que se refere à defesa de direitos sociais e trabalhistas. Em uma primeira leitura, creio que a sua apregoada adesão ao "socialismo" passava necessariamente pela sua defesa do direito do trabalho. No plano político, também não é difícil de estabelecer pontes entre as bandeiras radicais e a luta de Irineu em defesa do cidadão contra os desmandos do Estado e a oligarquização do poder.

Já no plano mais propriamente dito da atuação política, creio que seja pertinente nos determos um pouco mais na caracterização de nossos atores para, a partir daí, darmos prosseguimento ao nosso movimento de aproximações e afastamentos. Sobre este ponto em particular, acho que talvez seja o caso de pensarmos a lógica de atuação do radicalismo tendo em vista um fenômeno maior, qual seja o da constituição de instituições democráticas liberais nas quais as agremiações partidárias - tal como na acepção de Duverger ${ }^{31}$ - passam a assumir uma posição central quanto à questão da representação política das diferentes forças sociais. Nesse sentido, os partidos, independente dos seus programas e mesmo da sua origem, tendem a dirigir seus esforços, cada vez mais, para o interior das instituições, para as lutas político-legais. ${ }^{32}$ De uma forma geral, não creio que o partido radical tenha fugido a esse figurino.

Com base nessas reflexões, voltemos os olhos novamente para o nosso personagem-título. Como vimos acima, Irineu, em determinados momentos de sua carreira política, oscilou entre estar em uma posição de confrontação direta contra os detentores do poder, ou se posicionar junto às forças do situacionismo, como o fez durante os governos de Campos Sales e Rodrigues Alves. Porém, foi a partir da experiência civilista que afirmaria definitivamente a sua imagem pública como uma das principais lideranças de oposição. Para lançar seu nome nos pleitos eleitorais, ainda que em algumas ocasiões tenha se apresentado como candidato avulso, na maior parte das vezes, ofes por meio de uma agremiação eleitoral, seja naquelas que reuniam as diferentes lideranças locais em torno do poder - como o Partido Republicano Federal e o Partido

${ }^{31}$ Maurice Duverger, Os partidos políticos, Brasília, Editora da UnB, 1980.

${ }^{32}$ Conf. Pierre Rosanvallon, La démocracie des partis, in: Le peuple introuvable: histoire de la représentation démocratique en France, Paris, Éditions Gallimard, 1998, p. 171-217. 
Republicano do Distrito Federal -, seja na frustrada experiência de Rui Barbosa de reunir o "civilismo" em torno do Partido Republicano Liberal -, seja, finalmente ainda, em agremiações criadas à sua imagem e semelhança, cuja denominação, não poderia deixar de ser, era Partido Independente.

A par do envolvimento direto ou indireto de Irineu com articulações golpistas nas conjunturas críticas dos anos de 1897 e 1921, é possível afirmar que a tônica de sua atuação política - como a de uma plêiade de lideranças com perfil semelhante ao seu na Primeira República -, foi a de concentrar a sua atuação política no plano legal; daí, portanto, sua destacada carreira como líder parlamentar.

Para finalizar, cabe o registro, também breve, de dois pontos que podem servir de objeto para futuros estudos a respeito do personagem-título deste texto. A meu ver, uma possível chave explicativa para melhor compreender a maneira pela qual Irineu entendeu e fez política, é vê-lo como um ator político que, como poucos na Primeira República, soube se movimentar e se valer tanto de uma retórica dirigida para o conjunto dos eleitores, como da prática de arregimentação de clientelas junto aos estudantes e operários. (Como observação, me parece algo a se levar em conta o orgulho com que ele, como muitos em sua época, cultivava um fornido cadastro de eleitores.) Creio, portanto, que se poderia pensá-lo como uma figura que bem expressa a síntese dessas duas "gramáticas políticas", como nos termos sugeridos por Edson Nunes. ${ }^{33}$

Outra possível linha de investigação seria a de testar a hipótese aqui levantada com vistas a melhor examinar a natureza das relações que Irineu Machado estabeleceu tanto com figuras que como ele giraram em torno da órbita do Correio da Manhã, como com Edmundo Bittencourt e o próprio Correio. À primeira vista, me parece que um ponto de convergência que reunia todos esses atores - e aqui me refiro também a nomes como os dos ex-militares e políticos paraense e pernambucano Lauro Sodré e Barbosa Lima, o do jornalista Maurício de Lacerda, ou mesmo o do médico carioca Azevedo Lima, entre outros - era, antes de tudo, a crença na arena parlamentar como instrumento fundamental para a defesa dos direitos republicanos do povo brasileiro.

${ }^{33}$ Conf. Edson Nunes, Gramática Política do Brasil: clientelismo e insulamento burocrático, Rio de Janeiro, Jorge Zahar, 1997. 